\title{
Transient Hyperthyroidism in a Patient Taking Dietary Supplements Containing Kelp
}

\section{B. Clair Eliason, $M D$}

Dietary supplements, including a variety of vitamins, minerals, herbal products, tissue extracts, and proteins and amino acids, are sold in health food stores as well as a variety of other locations, and trade in supplements has grown into a multibillion dollar industry. ${ }^{1}$ Although government regulations do not require proof of safety or efficacy for these products, they do require proper labeling and sanitary production methods. ${ }^{2-4}$ Most supplements appear to be safe, but the toxic reactions that are occasionally reported ${ }^{5}$ are a concern. Of the many Americans who consume supplements for health benefits, more than $50 \%$ typically do not consult with their physician before taking them. ${ }^{6,7}$

Kelp, or seaweed, has long been used as a dietary supplement, particularly in Asian countries, where it is often consumed as a food. ${ }^{8} \mathrm{Kelp}$, which contains a large amount of iodine ${ }^{9}$ and is touted as having beneficial vitamins, minerals, and chemicals, ${ }^{10}$ is included in many of these supplements. Reported here is a case report of probable transient hyperthyroidism induced in a patient taking kelp from two different supplements.

\section{Case Report}

A 27-year-old woman complained of a gradual onset of fatigue that developed during the 2 months preceding her office visit. Except for a medical history of glomerulonephritis in the remote past, her medical history was otherwise unremarkable, and she was in no apparent distress. Her weight was 158 pounds, pulse 68 beats per minute, and blood pressure 116/80 mmHg. Findings on the remainder of the examination, including her thyroid, were normal, and there were no other signs of thyroid disease. Laboratory tests included thyroidstimulating hormone (TSH), complete blood cell

Submitted, revised, 3 March 1998.

From the Department of Family and Community Medicine, Medical College of Wisconsin, Milwaukee. Address reprint requests to $\mathrm{B}$. Clair Eliason, $M D$, Department of Family and Community Medicine, Medical College of Wisconsin, 1000 N 92nd St, Milwaukee, WI 53226-0509. count, and urinalysis. The urinalysis and complete blood cell count were normal, but the TSH was suppressed at $0.32 \mu \mathrm{IU} / \mathrm{mL}$ (normal 0.49 to $4.67 \mu \mathrm{IU} / \mathrm{mL}$ ).

At a follow-up office visit 10 days later, the patient brought three dietary supplements with her: a multivitamin, a supplement called Energy-V, and a supplement called HSN-W. She had visited an herbal doctor approximately 1 month previously, who had recommended Energy $V$ to help the fatigue and the HSN-W to strengthen her nails. According to the label, Energy V contained Siberian ginseng root, bee pollen, yellow dock root, licorice root, gota kola herb, kelp plant, schizandra fruit, barley grass, rose hips, and capsicum fruit. The multivitamin, which she had been taking for some time, also contained kelp. A repeated TSH level at this time was $0.81 \mu \mathrm{IU} / \mathrm{mL}$. The triiodothyronine $\left(\mathrm{T}_{3}\right)$ level was increased to $147 \mathrm{ng} / \mathrm{dL}$ (normal 4.5 to 137$)$ and her free thyroxine $\left(\mathrm{T}_{4}\right)$ level was 1.2 $\mathrm{ng} / \mathrm{dL}$ (normal 0.7 to $1.9 \mathrm{ng} / \mathrm{dL}$ ). Because of possible iodine-induced hyperthyroidism, the two supplements containing kelp were discontinued. She continued taking the third supplement, HSN-W, at her request.

The patient returned 3 weeks later, after having stopped the supplements, and reported several episodes of heart palpitations as her chief complaint. She stated that she had not taken the two supplements containing kelp since her previous visit. The nurse taking her vital signs found an irregular heart beat and a pulse of 84 beats per minute. Findings on her physical examination by the physician, including heart rate, were normal. She was told to remain off the kelp-containing supplements and return in 4 weeks.

When she returned 4 weeks later ( 7 weeks after stopping the supplements), she said she felt much better, and both the fatigue and heart palpitations had completely subsided. Her physical examination findings were normal, and her TSH, free $\mathrm{T}_{4}$, and $T_{3}$ levels were all within normal limits. She subsequently has continued to feel well up to the time of this report, 8 months later. Figure 1 dis- 
plays the temporal relations between ingestion of ingested kelp, with estimated daily doses of iodine, and clinical and laboratory findings.

\section{Discussion}

Iodine is part of the thyroxine molecule and is essential in thyroid metabolism. Prolonged dietary deficiencies of iodine can lead to hypothyroidism. Supplementation of iodine in the US diet with iodized salt has resulted in extremely rare cases of dietary iodine deficiency. The minimal recommended daily allowance (RDA) for iodine is 80 to $100 \mu \mathrm{g}$, with the average American diet containing between 300 and $700 \mu \mathrm{g} .{ }^{11}$ Doses of iodine that greatly exceed the RDA can lead to hypothyroidism or hyperthyroidism. ${ }^{11}$ The Wolff-Chaikoff effect is the inhibition of thyroxine production by large doses of iodide. ${ }^{11}$ Iodide therapy has also long been used to treat thyrotoxicosis, particularly thyroid storm. ${ }^{11}$ Some patients who are exposed to large doses of iodine for long periods will develop chronic hypothyroidism and thyroiditis. ${ }^{8}$

Large doses of iodine have been shown at times to precipitate hyperthyroidism. Cases of iodine-induced hyperthyroidism have occurred in patients with autonomous nodular elements and preexistent endemic goiter, with a normal (iodine-sufficient) thyroid gland, and with multinodular Graves' disease. ${ }^{11}$ Although most patients receiving large doses of iodine have their production of thyroxine suppressed and become hypothyroid, a few respond with increased thyroid production, most typically an increased $T_{3}$ in relation to $T_{4}{ }^{12,13}$

Kelp, a type of seaweed that can be eaten raw, is commonly consumed in Asia. ${ }^{8,13}$ In the United States it is more often dried, ground, and formulated into a tablet or capsule and then combined with vitamins, minerals, and other supplements. Alone, kelp is thought to be a rich source of vitamins, minerals, trace elements, and, of course, iodine. ${ }^{10}$ Lee et $\mathrm{al}^{9}$ reported from Great Britain that the average kelp-based supplement contained $1000 \mu \mathrm{g}$ of iodine (about 10 times the RDA).

It is unknown how much kelp Americans are consuming when they take nutritional supplements. In a telephone survey of 136 customers using two health food stores in the Milwaukee area, 3 were taking supplements containing kelp. ${ }^{6}$ Others might have had kelp in their multivitamins but were unaware of it and simply reported that they were taking a multivitamin. If the average kelp

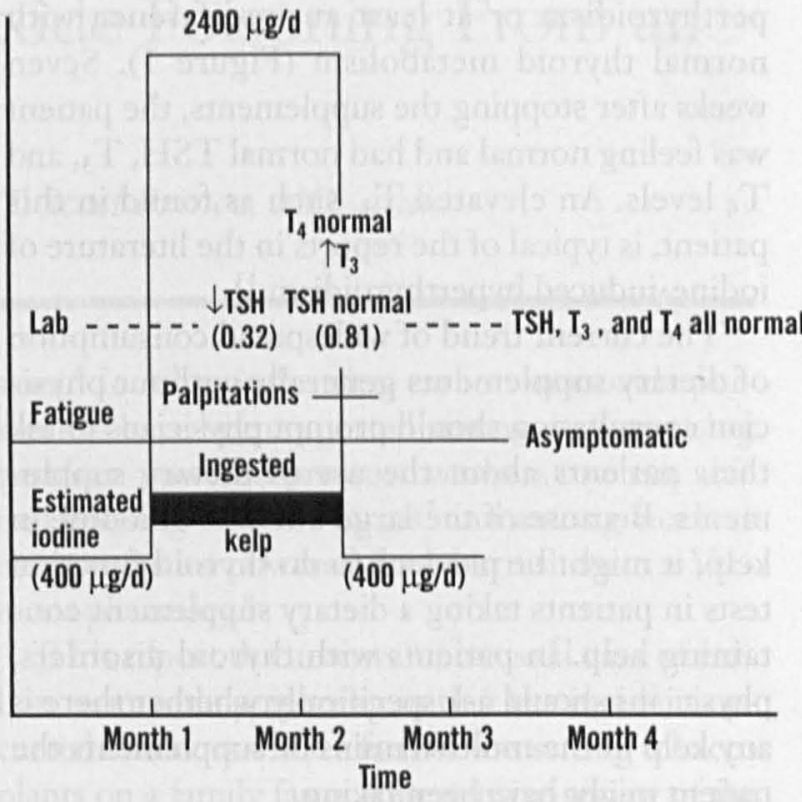

Figure 1. Relation between ingestion of kelp-containing supplements, with estimated daily dose of iodine, and thyroid hormone levels.

supplement contains $1000 \mu \mathrm{g}$ of iodine, ${ }^{9}$ the patient in this report was taking an estimated 2400 $\mu \mathrm{g} / \mathrm{d}$ including dietary sources. The recommended iodine dose for treating preoperative Graves disease is $1500 \mu \mathrm{g} / \mathrm{d}^{11}$

In a 31-year (1966 through 1997) MEDLINE search, there were four reports of patients developing hyperthyroidism while taking kelp as a dietary supplement. Two reports were from the Netherlands, ${ }^{14,15}$ one was from Japan, ${ }^{13}$ and one was from the United States. ${ }^{12}$ The case report from the United States was of a 72-year-old woman who developed clinical and laboratory evidence of hyperthyroidism while taking a kelpcontaining supplement. Six months after stopping the kelp, her thyroid function was normal. The other case reports also show a temporal relation between the ingestion of kelp and development of clinical and laboratory signs of hyperthyroidism, with subsequent normalization of thyroid function when the kelp is discontinued.

The case reported here did not provide unequivocal proof of iodine-provoked hyperthyroidism from kelp supplementation. The findings are, however, suggestive. The chronologic relation between the consumption of kelp supplements, suppressed TSH, and elevated $\mathrm{T}_{3} 10$ days later, combined with an intermittent palpitation experienced by the patient, indicates transient hy- 
perthyroidism or at least an interference with normal thyroid metabolism (Figure 1). Seven weeks after stopping the supplements, the patient was feeling normal and had normal TSH, $\mathrm{T}_{3}$, and $T_{4}$ levels. An elevated $T_{3}$, such as found in this patient, is typical of the reports in the literature of iodine-induced hyperthyroidism. ${ }^{13}$

The current trend of widespread consumption of dietary supplements generally without physician consultation should prompt physicians to ask their patients about the use of dietary supplements. Because of the large amount of iodine in kelp, it might be prudent to do thyroid function tests in patients taking a dietary supplement containing kelp. In patients with thyroid disorders, physicians should ask specifically whether there is any kelp in the multivitamins or supplements the patient might have been taking.

\section{References}

1. Blumenthal M, Riggins CW. Popular herbs in the US. In: Market therapeutic monograph. Austin, Tex: American Botanical Council, 1997.

2. Marwick C. Growing use of medicinal botanicals forces assessment by drug regulators. JAMA 1995; 273:607-9.

3. Porter D. Dietary Supplement Health and Education Act of 1994 (DSHEA). Pub Law no. 103-417, 108 Stat 4325.

4. David A. Kessler, Commissioner, Food and Drug Administration. Statement read before the subcommittee on health and the environment. United States House of Representatives, 29 July 1993.

5. Eliason BC, Doenier JA, Nuhlicek DN. Desiccated thyroid in a nutritional supplement. J Fam Pract 1994;38:287-8.

6. Eliason BC, Kruger J, Mark D, Rasmann DN. Dietary supplement users: demographics, product use and medical system interaction. J Am Board Fam Pract 1997;10:265-71.

7. Eliason BC, Myszkowski J, Marbella A, Rasmann DN. Use of dietary supplements by patients in a family practice clinic. J Am Board Fam Pract 1996; 9:249-53.

8. Konno N, Makita H, Yuri K, lizuka N, Kawasaki K. Association between dietary iodine intake and prevalence of subclinical hypothyroidism in the costal region of Japan. $\mathrm{J}$ Clin Endocrinol Metab 1994;78:393-7.

9. Lee SM, Lewis J, Buss DH, Holcombe GD, Lawrance $\mathrm{PR}$. Iodine in British foods and diets. $\mathrm{Br} \mathrm{J}$ Nutr 1994;72:435-46.

10. Balch JF, Balch PA. Prescription for nutritional healing: a practical $\mathrm{A}-\mathrm{Z}$ reference to drug-free remedies using vitamins, herbs, and food supplements. Garden City Park, NY: Avery, 1990.

11. Falk SA, editor. Thyroid disease: endocrinology, surgery, nuclear medicine, and radiotherapy. New York: Lippincott-Raven, 1990.

12. Shilo $S$, Hirsch HJ. Iodine-induced hyperthyroidism in a patient with a normal thyroid gland. Postgrad Med J 1986;62:661-2.

13. Ishizuki $\mathrm{Y}$, Yamauchi K, Miura Y. Transient thyrotoxicosis induced by Japanese dombu. Nippon Naibunpi Gakkai Zasshi 1989;65:91-8.

14. Hartman AA. [Hyperthyroidism during administration of kelp tablets.] Ned Tijdschr Geneeskd 1990;134:1373.

15. de Smet PA, Stricker BH, Wilderink F, Wiersinga WM. [Hyperthyroidism during treatment with kelp tablets.] Ned Tijldschr Geneeskd 1990;134:1058-9. 